\title{
Overexpression of $S P A R C$ protein contrasts with its transcriptional silencing by aberrant hypermethylation of SPARC CpG-rich region in endometrial carcinoma
}

\author{
FRANCISCO-JAVIER RODRÍGUEZ-JIMÉNEZ ${ }^{1}$, TRINIDAD CALDÉS ${ }^{2}$, PILAR INIESTA ${ }^{1}$, \\ JOSE ANTONIO VIDART ${ }^{3}$, JOSÉ LÓPEZ GARCIA-ASENJO ${ }^{4}$ and MANUEL BENITO ${ }^{1}$
}

\author{
${ }^{1}$ Departamento de Bioquímica y Biología Molecular, Facultad de Farmacia, Universidad Complutense de Madrid; \\ Servicio de ${ }^{2}$ Oncología, ${ }^{3}$ Ginecología and ${ }^{4}$ Anatomía Patológica, Hospital Universitario San Carlos, 28040 Madrid, Spain
}

Received November 15, 2006; Accepted December 18, 2006

\begin{abstract}
Secreted protein acidic and rich in cysteine (SPARC) is a secreted matricellular glycoprotein involved in crucial processes that occur during cancer. This study explored the occurrence of deregulated expression of SPARC in endometrial carcinomas, since it has been associated with the progression of other tumor types. We analyzed the expression of SPARC in endometrial carcinomas by TaqMan, Western blotting and immunohistochemistry. The $\mathrm{CpG}$ island methylation status of SPARC was evaluated by bisulfite sequencing method. A significant down-regulation of SPARC mRNA expression $(\mathrm{p}<0.001)$ was observed in endometrial tumor tissues, regardless of their microsatellite instability status (MSI). The downregulation can be accounted for by aberrant hypermethylation of its CpG-rich region, since we demonstrate that SPARC is a frequent target of this epigenetic event in this pathology. Although, differential expression of SPARC is already known in other cancer types, we report that down-regulation of the SPARC gene in endometrial tumors, formed by at least $80 \%$ of epithelial tumor cells, contrasts with a frequent overexpression of SPARC protein, with strong immunoreactivity in stromal cells. These results indicate a cell type specific expression of SPARC in endometrial carcinomas. Accumulation of SPARC protein in most tumors compared to normal tissues $(p<0.025)$, suggests an important role in the carcinogenesis of endometrial tumors. SPARC overexpression can be a useful molecular tool that may contribute to the diagnosis of this disease.
\end{abstract}

\section{Introduction}

Endometrial cancer, which originates in the inner lining of the uterus, accounts for approximately $90 \%$ of uterine cancers

Correspondence to: Professor Manuel Benito, Departamento de Bioquímica y Biología Molecular, Facultad de Farmacia, Universidad Complutense, 28040 Madrid, Spain

E-mail: benito@farm.ucm.es

Key words: SPARC, microsatellite instability, hypermethylation, endometrium and is the most common tumoral pathology that originates in the female reproductive system. The identification of proteins with different expression profiles between normal endometrium and endometrial carcinoma seems to be crucial for the understanding of the events occurring during the onset and progression of this pathology.

SPARC is a secreted matricellular glycoprotein which has been associated with the progression of various cancers. SPARC is not structurally involved in the extracellular matrix (ECM), but modulates its interactions with cells. SPARC interacts with other components of ECM (1) and stimulates endothelial cell adhesion disassembly $(2,3)$. The role of SPARC in cancer is controversial. This molecule promotes angiogenesis, a process that favours tumor growth $(4,5)$. In addition, it has recently been reported that SPARC produced by human melanoma cells impairs recruitment and antitumor cytotoxic activity of polymorphonuclear leukocytes (6). On the other hand, SPARC inhibited cell cycle in glioma (7) and showed suppressing activity in human ovarian cancer $(8,9)$. Regarding this, it has been suggested by Suzuki et al (10) that SPARC can act similarly to TGF- $ß$ (11) as tumor suppressor or oncogene depending on tumor phase. SPARC has effects on tissue remodelling and wound healing (12). In fact, enhanced epidermal closure was observed in SPARC null mice (13). The observed results may be related to their capability for modulation of angiogenesis and ECM formation, both events present during the carcinogenic process (14).

Epigenetic changes, in particular hypermethylation of $\mathrm{CpG}$ islands, have been considered as a possible regulatory mechanism for the expression of a large number of genes during the carcinogenic process (15). Methylation at $\mathrm{CpG}$ sites in the $5^{\prime}$ region is associated with gene silencing by interfering with transcription initiation. This molecular event represses a large repertoire of tumor suppressor genes expressed in different tumor types (16). Indeed, SPARC is epigenetically silenced through DNA methylation in pancreatic adenocarcinoma (17) and lung cancers (10). Microsatellite instability (MSI) is a molecular phenotype present in approximately $20 \%$ of sporadic endometrial cancers. MSI has been considered as an indicator of recurrence in sporadic endometrial cancers (18). Discordance between SPARC transcripts and protein content has been previously reported in different 
carcinomas, where there was loss of SPARC mRNA expression in cancer cells because abnormal methylation was correlated with a pronounced protein expression in the peritumoral stromal cells $(10,17)$. We studied the expression pattern of SPARC mRNA in endometrial tumors formed by $>80 \%$ of epithelial tumor cells and classified concerning their MSI status. We evaluated the methylation status of a $\mathrm{CpG}$-rich region of $S P A R C$ that may explain, at least partially, the down-regulation of the SPARC gene in these tumors. These results contrast with frequent overexpression of SPARC protein and with strong immunoreactivity in stromal cells of endometrial tumors.

\section{Materials and methods}

Tissue samples. Endometrial cancer tissues and their corresponding control samples were obtained from 29 patients who underwent surgery at San Carlos Hospital in Madrid. This study was approved by the ethics committee at the hospital, and informed consent was obtained prior to investigation. After surgical resection, samples were immediately embedded in TissueTek OCT medium (Sakura, Tokyo, Japan) and snap frozen at $-80^{\circ} \mathrm{C}$. Cryostat-sectioned, hematoxylin-eosin-stained samples from each tumor block were examined microscopically by two independent pathologists to confirm the presence of $>80 \%$ tumor cells. For gene expression analysis, tumors with less percentage of epithelial tumor cells were not included in the study. Paired normal tissues from the same patient, used as controls, were microscopically confirmed.

RNA and DNA isolation. Total-RNA was obtained from 29 homogenized frozen tissues by using Trizol solution (Invitrogen, Spain). Homogenates were incubated for $15 \mathrm{~min}$ on ice and then 1/5 volume of chlorophorm was added after vigorous shaking for $5 \mathrm{~min}$. The inorganic phase was separated by centrifugation at $12000 \mathrm{x} \mathrm{g}$ for $20 \mathrm{~min}$ at $4^{\circ} \mathrm{C}$. RNA was then precipitated using a volume of isopropanol and centrifuged at $10000 \mathrm{x} \mathrm{g}$ for $30 \mathrm{~min}$ at $4^{\circ} \mathrm{C}$. RNA pellets were washed with $75 \%$ cold ethanol and then dissolved in diethyl pyrocarbonate water. For the genomic DNA extraction, the aqueous phase was removed. Subsequently, $0.3 \mathrm{ml} 100 \%$ ethanol per $\mathrm{ml}$ Trizol was added, mixed and centrifuged at full speed at $4^{\circ} \mathrm{C}$. Pellets were treated with $1 \mathrm{ml} 0.1 \mathrm{M}$ sodium citrate in $10 \%$ ethanol per ml Trizol. Samples were washed with Solution B (0.075 M NaCl, 0.024 M EDTA). Then, $300 \mu 1$ Solution B per ml Trizol, $10 \mu \mathrm{l}$ SDS $20 \%$ and $5 \mu \mathrm{l}$ proteinase $\mathrm{K}(20 \mathrm{mg} / \mathrm{ml})$ were added for a better recovering of genomic DNA. Samples were precipitated with a volume of isopropanol and washed with ethanol $75 \%$. Pellets were resuspended in MilliQ sterile water. The quality of the extracted RNA was checked by Bioanalyzer 2100 (Agilent Technologies).

Microsatellite analysis. Tumors were classified according to their MSI status in two groups: replication error positive $\left(\mathrm{RER}^{+}\right)$and negative (RER-). Genomic DNA was isolated as previously described and used as a template in a multiplex PCR to investigate the MSI status. The amplified targets are five polymorphic human repeat DNA markers that includes the microsatellite loci BAT25, BAT26, D5S346 (APC), D17S250 (Mfd15CA) and D2S123. This panel is recommended as reference by the American Joint Commission on Cancer. PCR products were amplified using the HNPCC MSI test (Roche Diagnostics, Mannhein, Germany). Fluorescent labelled PCR products were analyzed by ABI PRISM 310 Genetic analyser (Applied Biosystems). MSI status was established when DNA sequences obtained from tumor samples were compared to the corresponding DNA sequences from normal samples. Evaluation of the results was performed based on the same criteria that we previously reported (19).

Real-time PCR (TaqMan). Total-RNA obtained from normal and tumoral tissues from 29 patients was independently reverse transcribed using TaqMan reverse transcription reagents (Applied Biosystems, NJ, USA) following the manufacturer's instructions. The pool of endometrial normal tissues used as a reference was formed by cDNA from 10 randomly selected normal tissues of different patients. Analysis was performed with the ABI PRISM 7700 Sequence Detection System instrument and software (Applied Biosystems, Foster City, CA) using the manufacturer's recommended conditions. Each reaction was performed in duplicate and as two independent experiments. cDNA (40 ng) was used as a template. TaqMan reactions for the target and housekeeping genes were prepared in separate tubes. MGB 'Assay on demand' probes were purchased (Applied Biosystems): SPARC (Hs00234160 ml); GAPDH (Hs99999905 ml). The comparative threshold cycle $\left(\mathrm{C}_{\mathrm{T}}\right)$ method was used to calculate the relative expression. For quantification of gene expression, the target gene (SPARC) value normalized to the expression of an endogenous reference $(G A P D H)$ was designated as $\Delta \mathrm{C}_{\mathrm{T}}\left[\Delta \mathrm{C}_{\mathrm{T}}=\mathrm{C}_{\mathrm{T}}\right.$ (test gene) $-\mathrm{C}_{\mathrm{T}}$ $(G A P D H)] . \Delta \mathrm{C}_{\mathrm{T}}$ for tumoral samples was then subtracted from the $\Delta \mathrm{C}_{\mathrm{T}}$ for the normal samples to generate $\Delta \Delta \mathrm{C}_{\mathrm{T}}\left[\Delta \Delta \mathrm{C}_{\mathrm{T}}=\right.$ $\Delta \mathrm{C}_{\mathrm{T}}$ (tumor) $-\Delta \mathrm{C}_{\mathrm{T}}$ (normal)]. The mean of these $\Delta \Delta \mathrm{C}_{\mathrm{T}}$ measurements was used to calculate the relative expression, $2^{-\Delta \Delta \mathrm{CT} \text {. }}$

Western blot analysis. Pieces of frozen normal and tumoral tissues were homogenized in RIPA buffer (Sigma). Samples were centrifuged at $10000 \mathrm{x}$ g for $30 \mathrm{~min}$. The supernatant was collected and relative protein concentration was determined using Bio-Rad protein assay reagent following the manufacturer's instructions. Lysate $(100 \mu \mathrm{g})$ from normal and tumoral tissues was denatured and loaded on $12 \%$ SDSpolyacrylamide gel under reducing conditions. Subsequently, proteins were electrophoretically transferred to a PVDF membrane. The membrane was blocked with 3\% skim milk in TBST for $90 \mathrm{~min}$ and probed overnight with an anti-SPARC antibody (ON1, ZYMED Laboratories, San Francisco) (diluted 1:250 in 0.3\% skim milk in TBST). Subsequently, the membrane was incubated with peroxidase-labelled antimouse secondary antibody (1:200). The blots were visualized by the ECL (Amersham, UK) detection system. Results were quantified by densitometry using the Quantity One software.

Immunohistochemistry. Frozen sections $(5 \mu \mathrm{m})$ from 10 patients were cut from tumor and their corresponding normal endometrial tissues. Tissues were examined by immunohistochemistry using the avidin-biotin complex (ABC) (PK-6102, Vector Laboratories). Sections were air dried and fixed in acetone during $5 \mathrm{~min}$. Endogenous peroxidases were blocked in PBS with $3 \% \mathrm{H}_{2} \mathrm{O}_{2}$ for $10 \mathrm{~min}$. Samples were incubated with 
a

mRNA expression of SPARC in RER-endometrial cancer

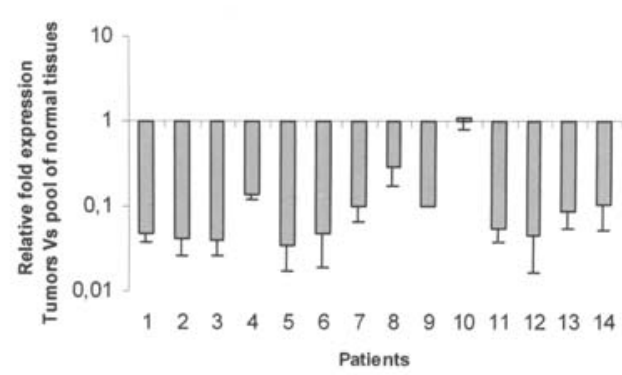

C b

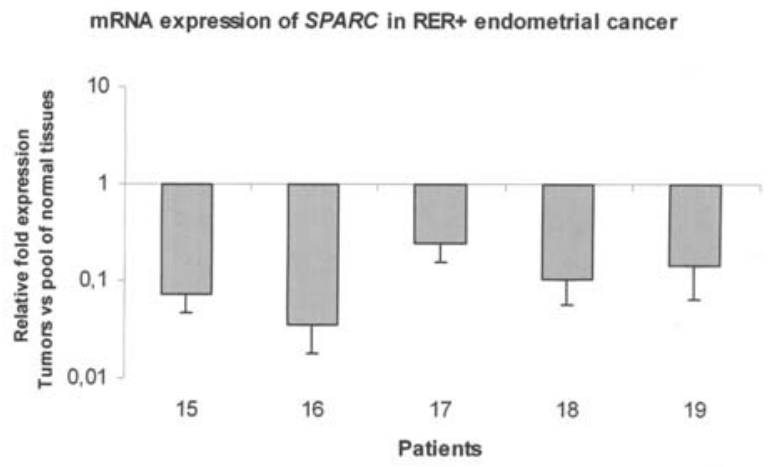

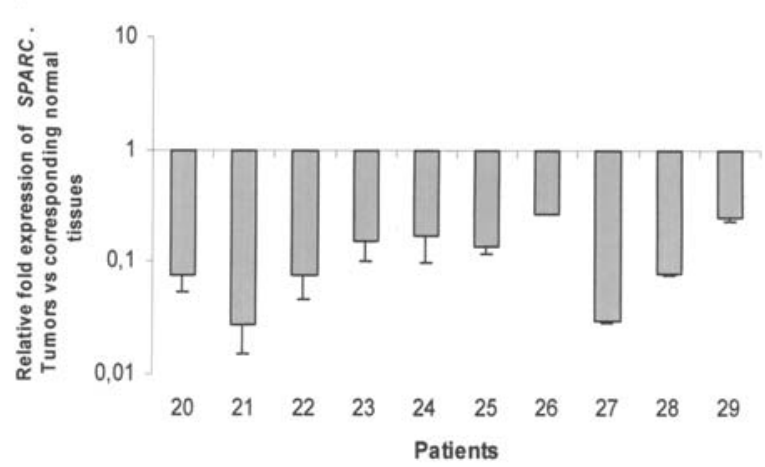

Figure 1. Relative fold reduction of SPARC mRNA in endometrial tumors. (a) Down-regulation of SPARC in RER- endometrial tumors, compared with a pool of normal tissues. (b) Down-regulation of SPARC in RER ${ }^{+}$endometrial tumors, compared with a pool of normal tissues. (c) Down-regulation of SPARC in endometrial tumors compared with their corresponding normal tissue and independently of their MSI status. Data was normalized by the values of $\mathrm{C}_{\mathrm{T}}$ for $\operatorname{GAPDH}\left(\Delta \mathrm{C}_{\mathrm{T}}\right)$. Relative fold changes were calculated using the formula: fold difference $=2-\Delta \Delta \mathrm{C}_{\mathrm{T}}$. Where $\Delta \Delta \mathrm{C}_{\mathrm{T}}=\mathrm{C}_{\mathrm{T}}$ (tumors) - $\mathrm{C}_{\mathrm{T}}$ (pool of 10 normal tissues) for (a) and (b). $\Delta \Delta \mathrm{C}_{\mathrm{T}}=\mathrm{C}_{\mathrm{T}}$ (tumors) - $\mathrm{C}_{\mathrm{T}}$ (corresponding normal tissue) for (c).

blocking solution $(50 \mu 1$ of normal serum from mouse, $2.5 \mathrm{ml}$ of PBS) for $60 \mathrm{~min}$. Subsequently, 10 sections from normal and tumoral tissues were incubated overnight at $4{ }^{\circ} \mathrm{C}$ with anti-SPARC antibody (ON1, ZYMED Laboratories) (diluted 1:100). Then, they were washed thoroughly with PBST before application of the biotinylated secondary antibody (PK-6102, Vector Laboratories) and incubation for $45 \mathrm{~min}$. Sections were once again washed, before application of Avidin Biotin Complex, for $30 \mathrm{~min}$. The complex was drained off and the chromogen DAB (SK-4100, Vector Laboratories) was added for 2-10 min. Finally, samples were counterstained with haematoxylin and mounted with Mowiol.

$C p G$ island methylation analysis of the SPARC gene in endometrial tissues by bisulphite treatment and sequencing (BSP). Genomic DNA (1 $\mu \mathrm{g})$ was obtained from tumoral and normal tissues, as well as peripheral blood from patients included in the study. Then, genomic DNA was treated with sodium bisulphite by using the EZ DNA methylation kit (Zymo Research) following the manufacturer's instructions. Bisulphite-treated DNA was amplified with primers designed to both methylated and unmethylated DNA (BSP). A set of primers were designed to cover the CpG-rich dinucleotide region of the SPARC gene. Particularly, from the location 12229572-12229171 of the sequence with accession number: NT_029289.10, Hs5_29448. BSP SPARC sense primer (5'-GAT AGA GAT AGT TTT GGT TAT GGG A-3') and BSP SPARC antisense (5'-CCA
CCT TCT AAA AAA CAA CAA AC-3'). PCR products were then sub-cloned into pCR4-TOPO (Invitrogen, Spain) and DNA isolated from at least 4-10 clones for each normal and tumor tissue. Finally, samples were sequenced using the BigDye Terminator cycle sequencing kit (Applied Biosystems) and ABI 310 automated sequencer.

Statistical analysis. The different comparisons were assessed by Student's t-test. All p-values are derived from two-tailed statistical test using SPSS 11.5 software. A p-value $<0.05$ was considered statistically significant. Correlations were analyzed using the Pearson's coefficient.

\section{Results}

Expression of SPARC mRNA as well as SPARC protein were studied in normal and tumoral tissues obtained from patients with endometrial carcinomas. Using genomic DNA, tumors were classified according to their MSI status. We determined that $77 \%$ of the analyzed tumors were RER ${ }^{-}$and $23 \%$ were classified as RER ${ }^{+}$. RNA obtained from endometrial normal and tumoral tissues was converted to cDNA and amplified by real-time quantitative PCR (TaqMan).

Using exclusively tumors with $>80 \%$ of epithelial tumor cells, we observed that $98 \%$ of the evaluated tissues showed a statistically significant down-regulated expression pattern for $S P A R C$ in endometrial cancer, as compared to a pool of 


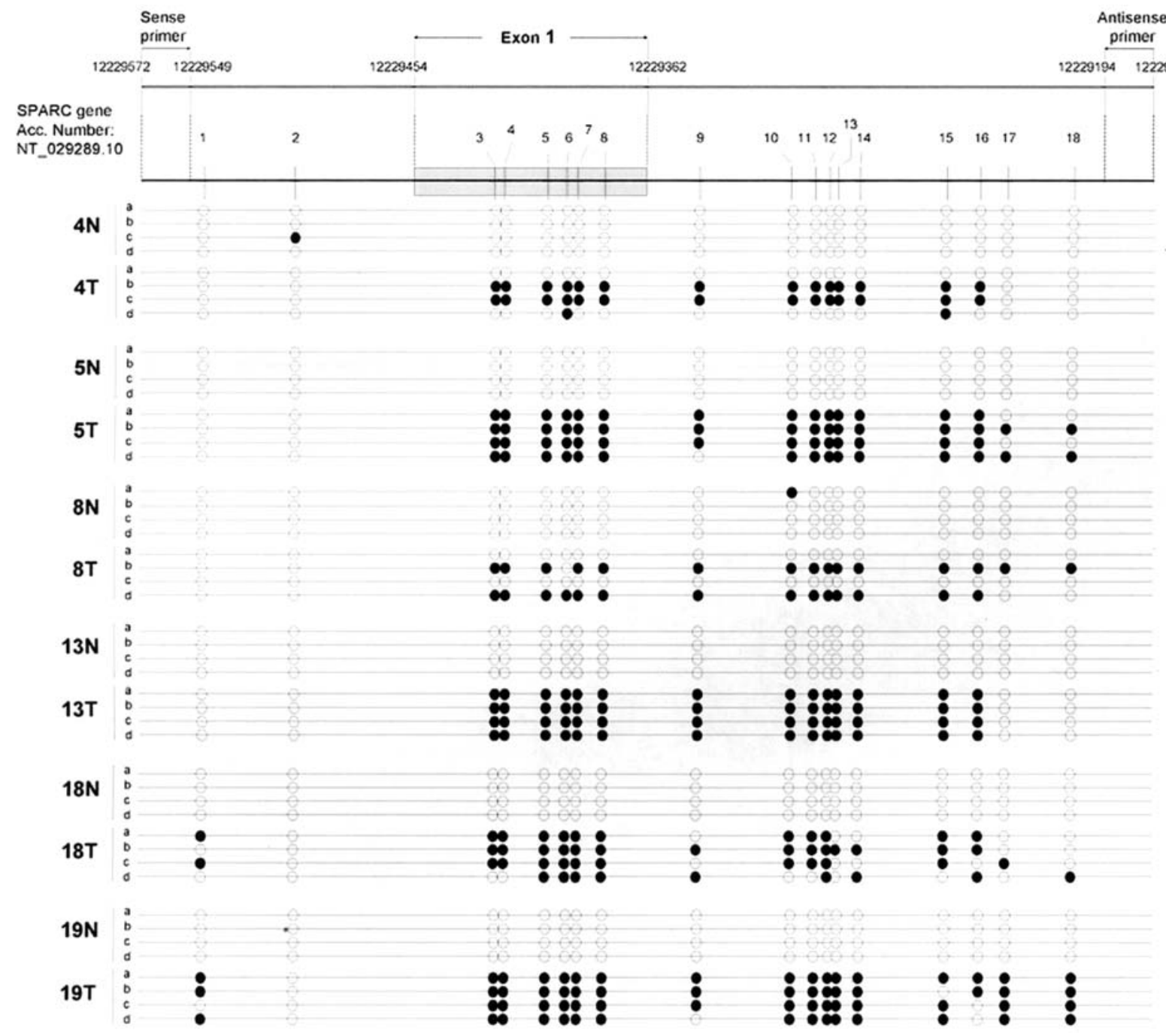

Figure 2. Genomic bisulfite sequencing of the $\mathrm{CpG}$ rich region of the SPARC gene in tumor and normal endometrial tissues. Representative positive cases of hypermethylated endometrial tumors compared to their corresponding normal tumors. The analyzed sequence spans $401 \mathrm{bp}$ and includes $18 \mathrm{CpG}$ sites. Exon 1 is depicted by the grey box. Fragments were subcloned, and at least 4 plasmid clones for each tissue specimen were sequenced. Each row represents one clone. Open and filled circles represent unmethylated or methylated CpGs, respectively. Patient numbers located on the left side correspond to those assigned during the study of mRNA expression. N, normal tissues; T, tumor tissues.

control tissues $(\mathrm{p}<0.001)$ (Fig. 1). Furthermore, when the expression of SPARC was compared between RER ${ }^{-}$and RER ${ }^{+}$ tumors, no significant differences in the expression level were obtained ( $\mathrm{p}>0.6$ and $>0.8$, respectively).

Therefore, we focused our interest on SPARC expression in endometrial carcinomas independently of their microsatellite instability. To confirm our previous results, we studied SPARC mRNA expression in 10 additional tumoral tissues and their normal pairs. A decrease of SPARC number of transcripts was again observed when the expression of endometrial tumors was compared to their corresponding normal tissues (Fig. 1c). Since down-regulated expression of gene suppressors in endometrial carcinomas has been explained by promoter hypermethylation (20), we investigated whether the SPARC gene was also hypermethylated in endometrial carcinomas in comparison with their normal tissues. For this purpose, we examined by BSP method a CpG-rich region of SPARC, of the sequence NT_029289.10, Hs5_29448 (5q31.3-q32) which includes exon 1, spanning a length of 401 bp (Fig. 2). Bisulfite genomic sequencing was performed on this region in tumors and their corresponding normal tissues. This analysis showed that $66 \%$ of the tumors were aberrantly methylated in the mentioned genomic region, in contrast with their corresponding normal tissue. We also studied the methylation status in DNA from peripheral blood and did not observe hypermethylation in any of these control samples (data not shown). The expression of SPARC protein was examined in human endometrial tumors, and we observed that $70 \%$ showed higher protein expression in tumoral than in non-tumoral tissues (Fig. 3). Values from the densitometric analysis were statistically evaluated and showed that the expression of SPARC in endometrial tumors was significantly higher than in normal tissues $(\mathrm{p}<0.025)$. Overexpression of SPARC protein in tumor samples was independent of their MSI status ( $p>0.15)$.

Consistent with the results obtained by Western blotting, the immunohistochemical analysis showed in $90 \%$ of the patients, a higher protein expression level in tumor tissue than in their corresponding normal specimen. Immunohistochemistry studies revealed that SPARC protein expression was constrained to stromal cells, presumably fibroblasts, of 

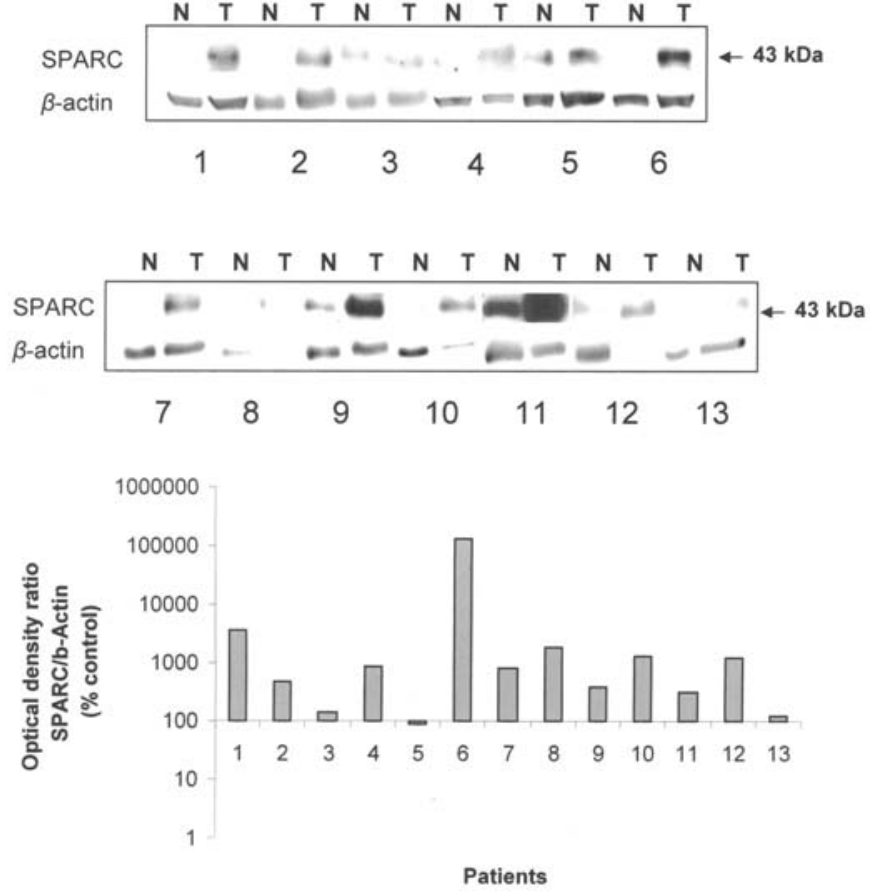

Figure 3. Protein level of SPARC in endometrial tumors compared to the corresponding adjacent normal tissues. Representative results from tumor and its corresponding normal tissue obtained by Western blotting. Graphics of the quantification of the optical density obtained from the corresponding bands are depicted below. Optical density was quantified using the image system Quantity One and normalized by the optical density of $\beta$-actin bands. tumor tissues. The immunostaining was more intense in the peritumoral stroma surrounding the neoplastic epithelium. No SPARC protein expression was detected in epithelial tumor cells (Fig. 4).

\section{Discussion}

Detection of DNA alterations is crucial to provide invaluable information about mechanisms involved in the beginning and evolution of each tumor. Among those, epigenetic alterations such as aberrant hypermethylation of the CpG-rich regions are of particular relevance, since this genetic alteration changes the gene transcription rate and has been etiologically related to the cancer process. Although, there is not much available information regarding epigenetic changes in endometrial cancer, the hypermethylation of some genes in this disease is known (20). For other cervical cancers, a correlation between hypermethylation of the $h T E R T$ gene and poorer outcome has been established (21). Very recently, it has been demonstrated that the SPARC gene showed aberrant methylation in a high proportion of invasive cervical cancers (22). Here we demonstrate that $S P A R C$ is a frequent target for aberrant methylation in endometrial cancer, a mechanism that may be a major cause for the observed down-regulation of SPARC. Therefore, we consider the hypermethylation of SPARC as a specific and also frequent molecular event in endometrial tumor tissues. Our results suggest that a SPARC methylation profile may be of potential help for early diagnosis of endometrial cancer. a

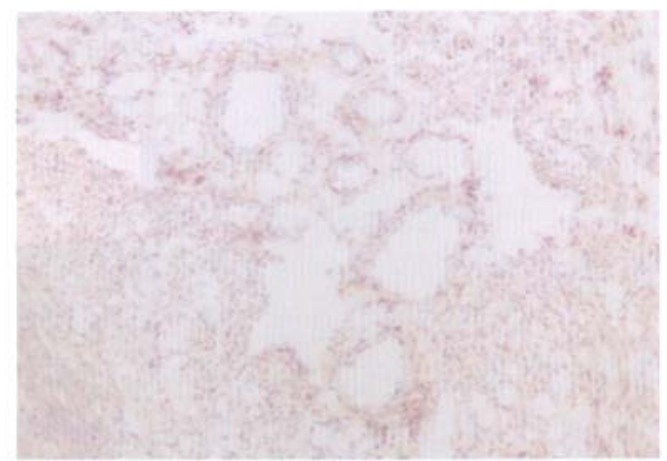

c

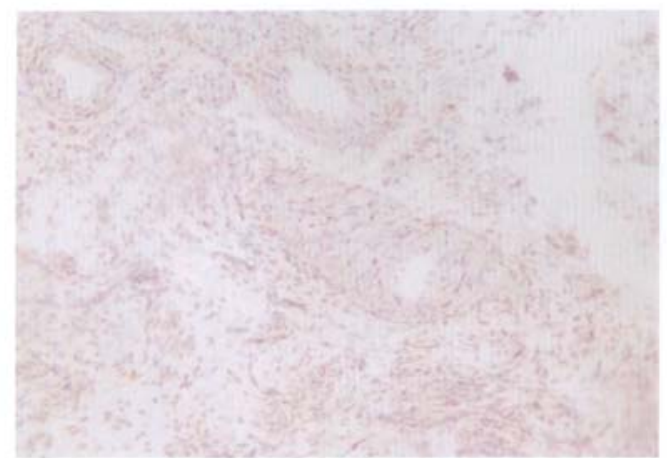

b

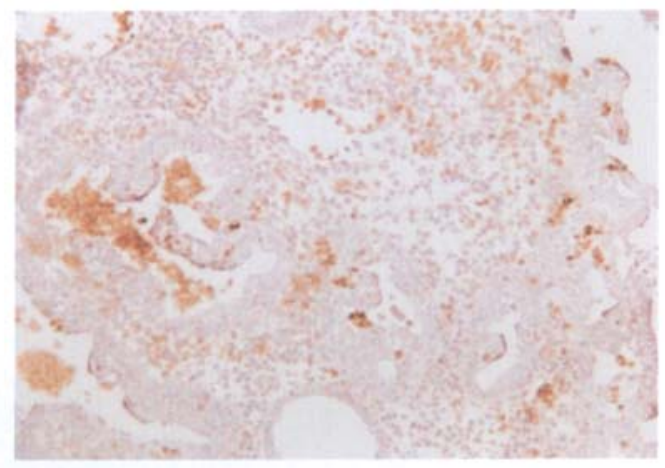

Figure 4. Immunolocalization of SPARC in human endometrial carcinoma and its matching normal endometrial tissue. Immunohistochemical procedure was performed in frozen sections using a dilution (1:100) SPARC-antibody. Slides were counterstained with hematoxylin. (a) No significant staining was observed in non-cancerous endometrium. (b) Strong immunoreactivity was detected in stromal fibroblasts (dark brown colour), in contrast with the negative neoplastic epithelium. (c) A control tumor tissue section incubated with PBS, mouse serum and secondary antibody did not show a signal beyond background. Original magnification $\mathrm{x} 200$. 
Some authors have established a correlation between presence of hypermethylation and microsatellite instability in sporadic endometrial cancers. For instance, silencing of transcription of the $h M L H 1$ gene by hypermethylation has been described in $\mathrm{RER}^{+}$sporadic endometrial carcinomas $(23,24)$. Another molecule, $S F R P 1$, is preferentially hypermethylated and down-regulated in MSI phenotype tumors (25). However, we find that aberrant hypermethylation and loss of SPARC mRNA expression was present in endometrial tumors, independently of their MSI status.

Surprisingly, Western blotting analysis demonstrated significant enhancement in the expression of SPARC in endometrial tumors compared to normal endometrial tissues. Discordant expression of SPARC mRNA and protein in endometrial carcinoma is consistent with previous results of studies performed in other carcinogenic tissues from different organs. Thus, in lung and pancreatic carcinomas, SPARC mRNA is down-regulated in cancer cells through a DNA methylation mechanism while the protein was up-regulated in stromal cells adjacent to cancer cells $(10,17)$. Another study showed that SPARC mRNA expression was not expressed by ovarian carcinoma or by surface epithelial cells, however, SPARC immunostaining was observed within their cytoplasm. Due to the fact that strong immunoreactivity was found in cytoplasm of stromal tumor cells, the authors suggested that SPARC secreted from stroma is internalized by epithelial cancer cells (26). Here we demonstrate that the expressing cells of SPARC protein in endometrial carcinomas, according to the immunolabeling, are the stroma cells surrounding epithelial cells of glands and lumen. Although, further studies must clarify the relevance of the presence of SPARC protein in stroma cells from the endometrial tumors, it has been suggested that it has a role as mediator of interactions among stromal fibroblast and cancer cells (17). Concerning the role of SPARC as mediator of interactions between stromal cells and cancer cells, it should be considered that SPARC is up-regulated during extracellular matrix remodelling; due to its counter-adhesive properties, SPARC modulates cellextracellular matrix interactions. This is a key mechanism, since the process of tumor invasion involves disengagement of the cells from their microenvironment, followed by breakdown of the surrounding matrix, cell movement, and re-establishment of the local environment at a new site, enabling tumor cells at the tumor-invasive front to overcome the extracellular matrix barrier, and penetrate adjacent tissues.

Dual up- and down-regulation of protein and mRNA expression in endometrial cancer complicates the interpretation of results. The lack of expression of SPARC mRNA in our cancer tissue samples compared to normal tissues may be explained by the presence of epithelial cancer cells always being above $80 \%$, discarding tumor samples with $>20 \%$ of stromal cells. The absence of correlation in endometrial tumors between the expression level of SPARC protein and its mRNA may be due to an initial excess of SPARC protein, produced by stromal cells, followed by a silencing on the transcriptional level through DNA methylation, contributing to the creation of an optimal cancer cell economy. It is plausible that aberrant methylation of SPARC and tumorstromal interactions might regulate the dual expression of this molecule in endometrial cancer. Other post-translational mechanisms which are not currently elucidated, such as upregulation of the translation process or reduction of protein degradation, might influence SPARC protein abundance in endometrial cancer tissues. We cannot rule out the possibility of a low level of transcripts but an increased mRNA stability in stromal cells causing a high level of SPARC protein in tumors. Since most of the evaluated tumor tissues showed an increased level of SPARC protein, it is possible that this molecule favours the tumorigenic process, playing a role in the etiopathology of endometrial carcinomas.

In conclusion, the overexpression of SPARC protein located in stromal cells, may contribute to the carcinogenic process in the endometrium, which can provide a tool for its molecular diagnosis.

\section{Acknowledgements}

The authors gratefully acknowledge Dr Mario Fernández Fraga for his help in the hypermethylation studies. We also recognize the grant support from Fundación de Investigación Médica Mutua Madrileña, Sanophy-Synthelabo, and Red Temática Cooperativa de Centros de Cáncer C03/010, Instituto Carlos III, Ministerio de Sanidad y Consumo, Spain.

\section{References}

1. Sage EH, Reed M, Funk SE, Truong T, Steadele M, Puolakkainen P, Maurice DH and Bassuk JA: Cleavage of the matricellular protein SPARC by matrix metalloproteinase 3 produces polypeptides that influence angiogenesis. J Biol Chem 278: 37849-37857, 2003.

2. Murphy-Ullrich JE, Lane TF, Pallero MA and Sage EH: SPARC mediates focal adhesion disassembly in endothelial cells through a follistatin-like region and the $\mathrm{Ca}\left(2^{+}\right)$-binding EF-hand. J Cell Biochem 57: 341-350, 1995.

3. Lane TF and Sage EH: Functional mapping of SPARC: peptides from two distinct $\mathrm{Ca}(+)$-binding sites modulate cell shape. J Cell Biol 111: 3065-3076, 1990.

4. Lane TF, Iruela-Arispe ML, Johnson RS and Sage EH: SPARC is a source of copper-binding peptides that stimulate angiogenesis. J Cell Biol 125: 929-943, 1994.

5. Iruela-Arispe ML, Lane TF, Redmond D, Reilly M, Bolender RP, Kavanagh TJ and Sage EH: Expression of SPARC during development of the chicken chorioallantoic membrane: evidence for regulated proteolysis in vivo. Mol Biol Cell 6: 327-343, 1995.

6. Alvarez MJ, Prada F, Salvatierra E, Bravo AI, Lutzky VP, Carbone C, Pitossi FJ, Chuluyan HE and Podhajcer OL: Secreted protein acidic and rich in cysteine produced by human melanoma cells modulates polymorphonuclear leukocyte recruitment and antitumor cytotoxic capacity. Cancer Res 65: 5123-5132, 2005.

7. Schultz C, Lemke N, Ge S, Golembieski WA and Rempel SA: Secreted protein acidic and rich in cysteine promotes glioma invasion and delays tumor growth in vivo. Cancer Res 62: 6270-6277, 2002.

8. Mok SC, Chan WY, Wong KK, Muto MG and Berkowitz RS: SPARC, an extracellular matrix protein with tumor-suppressing activity in human ovarian epithelial cells. Oncogene 12: 1895-1901, 1996.

9. Said N and Motamed K: Absence of host-secreted protein acidic and rich in cysteine (SPARC) augments peritoneal ovarian carcinomatosis. Am J Pathol 167: 1739-1752, 2005.

10. Suzuki M, Hao C, Takahashi T, Shigematsu H, Shivapurkar N, Sathyanarayana UG, Iizasa T, Fujisawa T, Hiroshima K and Gazdar AF: Aberrant methylation of SPARC in human lung cancers. Br J Cancer 92: 942-948, 2005.

11. Wakefield LM and Roberts AB: TGF- $\beta$ signalling: positive and negative effects on tumorigenesis. Curr Opin Genet Dev 12: 22-29, 2000 .

12. Reed MJ, Puolakkainen P, Lane TF, Dickerson D, Bornstein P and Sage EH: Differential expression of SPARC and thrombospondin 1 in wound repair: immunolocalization and in situ hybridization. J Histochem Cytochem 41: 1467-1477, 1993. 
13. Bradshaw AD, Reed MJ and Sage EH: SPARC-null mice exhibit accelerated cutaneous wound closure. J Histochem Cytochem 50: 875, 2002.

14. Puolakkainen PA, Bradshaw AD, Brekken RA, Reed MJ, Kyriakides T, Funk SE, Gooden MD, Vernon RB, Wight TN, Bornstein P and Sage EH: SPARC-thrombospondin-2-doublenull mice exhibit enhanced cutaneous wound healing and increased fibrovascular invasion of subcutaneous polyvinyl alcohol sponges. J Histochem Cytochem 53: 571-581, 2005.

15. Bird A: DNA methylation de novo. Science 286: 2287-2288, 1999.

16. Jones PA and Laird PW: Cancer epigenetics comes of age. Nat Genet 21: 163-167, 1999.

17. Sato N, Fukushima N, Maehara N, Matsubayashi H, Koopmann J, Su GH, Hruban RH and Goggins M: SPARC/osteonectin is a frequent target for aberrant methylation in pancreatic adenocarcinoma and a mediator of tumor-stromal interactions. Oncogene 22: 5021-5030, 2003.

18. Fiumicino S, Ercoli A, Ferrandina G, Hess P, Raspaglio G, Genuardi M, Rovella V, Bellacosa A, Cicchillitti L, Mancuso S, Bignami M and Scambia G: Microsatellite instability is an independent indicator of recurrence in sporadic stage I-II endometrial adenocarcinoma. J Clin Oncol 19: 1008-1014, 2001.

19. Moran A, Iniesta P, De Juan C, González-Quevedo R, Sánchez-Pernaute A, Díaz-Rubio E, Ramón y Cajal S, Torres A, Balibrea JL and Benito M: Stromelysin-1 promoter mutations impair gelatinase B activation in high microsatellite instability sporadic colorectal tumors. Cancer Res 62: 3855-3860, 2002.
20. Whitcomb BP, Mutch DG, Herzog TJ, Rader JS, Gibb RK and Goodfellow PJ: Frequent HOXA11 and THBS2 promoter methylation, and a methylator phenotype in endometrial adenocarcinoma. Clin Cancer Res 9: 2277-2287, 2003.

21. Widschwendter A, Muller HM, Hubalek MM, Wiedemair A, Fiegl H, Goebel G, Mueller-Holzner E, Marth C and Widschwendter M: Methylation status and expression of human telomerase reverse transcriptase in ovarian and cervical cancer. Gynecol Oncol 93: 407-416, 2004.

22. Sova P, Feng Q, Geiss G, Wood T, Strauss R, Rudolf V, Lieber A and Kiviat N: Discovery of novel methylation biomarkers in cervical carcinoma by global demethylation and microarray analysis. Cancer Epidemiol Biomarkers Prev 15: 114-123, 2006.

23. Esteller M, Levine R, Baylin SB, Ellenson LH and Herman JG: MLH1 promoter hypermethylation is associated with the microsatellite instability phenotype in sporadic endometrial carcinomas. Oncogene 17: 2413-2417, 1998.

24. Risinger JI, Berchuck A, Kohler MF, Watson P, Lynch HT and Boyd J: Genetic instability of microsatellites in endometrial carcinoma. Cancer Res 53: 5100-5103, 1993.

25. Risinger JI, Maxwell GL, Chandramouli GV, Aprelikova O, Litzi T, Umar A, Berchuck A and Barrett JC: Gene expression profiling of microsatellite unstable and microsatellite stable endometrial cancers indicates distinct pathways of aberrant signaling. Cancer Res 65: 5031-5037, 2005.

26. Brown TJ, Shaw PA, Karp X, Huynh MH, Begley H and Ringuette MJ: Activation of SPARC expression in reactive stroma associated with human epithelial ovarian cancer. Gynecol Oncol 75: 25-33, 1999. 